Citation: B.W. Ninham, R.M. Pashley (2020) IntroductionandBackground.About Water: Novel Water Technologies in the New Millennium. Substantia 4(2) Suppl.: 9-17. doi: 10.36253/Substantia-1123

Copyright: (c) 2020 B.W. Ninham, R.M. Pashley. This is an open access, peer-reviewed article published by Firenze University Press (http://www. fupress.com/substantia) and distributed under the terms of the Creative Commons Attribution License, which permits unrestricted use, distribution, and reproduction in any medium, provided the original author and source are credited.

Data Availability Statement: All relevant data are within the paper and its Supporting Information files.

Competing Interests: The Author(s) declare(s) no conflict of interest.

\section{Introduction and Background About Water: Novel Water Technologies in the New Millennium}

\author{
Barry W. Ninham ${ }^{1}$, Richard M. Pashley ${ }^{2, *}$ \\ ${ }^{1}$ Department of Applied Mathematics, Research School of Physical Sciences, Australian \\ National University, Canberra, Australia \\ ${ }^{2}$ School of Science, University of New South Wales, Northcott Drive, Campbell, Canberra, \\ Australia \\ *Corresponding author: r.pashley@adfa.edu.au
}

A year ago, May 24, 2019 was the $500^{\text {th }}$ anniversary of the death of Leonardo da Vinci. Visionary water projects on a grand scale were one of his lifelong passions. They were never fulfilled. Substantia offers this volume on new water technologies that work, in celebration of the life of da Vinci, the artist and genius of Florence.

These technologies are simple and cheap. They embrace desalination, sterilization of wastewater, including killing of viruses, selective heavy metal ion removal and harvesting.

And a simple solution to a major world economic problem. that of cavitation in ship propellers.

Our claims are startling and apply to real world conditions, that is, in concentrated and complex environments. They are not restricted to ideal, dilute solutions. They are presently inexplicable within the confines and boundaries of classical physical and colloid chemistry. It has been increasingly apparent that this venerable enabling discipline that underpins chemical engineering and biology suffers from sins of omission and commission. Once those strictures are removed whole new opportunities open up. Examples of these we want to exhibit here.

\section{ABOUT WATER}

In the early centuries of our Christian-Roman civilisation it is reported by Gibbon in Decline and Fall of the Roman Empire, that the bazaars of Byzantium, Alexandria and Antioch all buzzed with debate on the Nature of the Trinity. The matter was settled by the guidance of Constantine himself at the Council of Nicea in $351 \mathrm{AD}$ and, as we know, against the heresy of Arius.

At the present time the corresponding, though Godless, debate concerns the anticipated catastrophe of climate change. Regardless of which Creed tri- 
umphs here, pro climate change or sceptic, it is apparent that without clean water mankind is in for a terrible time.

The motivation is indisputable. Without clean water our future prospects, recalling the Biblical ten plagues of Egypt $^{1}$, are dire.

1. The History of Water in Civilisations has been documented with elegance and erudition by Mark Henry. We defer to his exceptional paper. ${ }^{1}$

\section{Water and Climate Change in Prehistory}

What is missing in Henry's paper are some sobering water related catastrophes of prehistory. It has recently been discovered that the Blue Nile did not flood for 30 years, during the Middle Kingdom of Egypt. The disaster was one from which Egyptian civilisation never quite recovered, not to speak of cannibalism, the loss of many cities and Nile tributaries. Similar events consumed civilisations of the middle east on the Euphrates and Tigris. The mighty Oxus of antiquity it now seems might even have been so large that it passed through the then Sea of Aral to the Caspian and on to the Black Sea. Its banks were lined with lost cities all the way to Afghanistan. Alexander's army it seems might have been able to row all the way to Central Asia. ${ }^{2}$

The sea of Aral has dried up permanently in the last 50 years due to Soviet exploitation of the Oxus for irrigating second grade cotton.

The Darling river in Australia, that country's longest river dried up this year for the same reason. The British Aswan dam, massively expanded by the Soviets has stopped the Nile from flooding - a catastrophe for Egypt and the $500 \mathrm{~km}$ dam so formed, for the Sudan. The Blue Nile is now dammed in Ethiopia with who knows what catastrophes are to follow in Egypt, as for Turkey's dam at the head of the Euphrates.

The Black Sea only filled up about 8000 years ago, taking out an entire civilisation in the process.

\section{A Perennial Problem with Water}

Why ice floats on water, without which life could not have evolved, was the subject of celebrated debate commissioned by Cosimo II de' Medici. It took place in Florence for a few days around Nov 5, 1611, between Galileo and an Aristotelian Professor. Galileo lost the

\footnotetext{
${ }^{1}$ God's punishment of the Egyptians from whom the enslaved Israelites who escaped across the Red Sea is given in the Jewish Passover services. They consisted of ten plagues: Blood, Boils, Frogs, Hail, Vermin, Locusts, Murrain (an infection of mucous membrane of intestines of sheep and cattle (substitute swine flu) Pestilence, Slaying of first born, Darkness.
}

debate, although he never admitted it. In almost a role reversal, a hubris-filled Galileo argued as an Aristo-Platonist, while his opponent appealed to experiment. ${ }^{3}$

The occasion was marked again 400 years later in Florence with an international conference. ${ }^{4}$ The matter remains unresolved. The only work that comes close to solving the problem is the little-known paper. $^{5}$

This is not accepted, as it is unconventional and not understood by a too conservative clientele obsessed with simulation as a valid occupation, and not familiar with older theories.

\section{Water and Oil}

The first experiment published was on clay tablets that dates back to the time of Hammurabi (a famous Akkadian ruler from the area which is now Iraq) around 18 th century before Christ. The priests studying oil on water spreading (pouring water in oil and oil in water) were among other things interested in predicting the future. For instance, if one small and one large drop emerged a male child would be born. There were lots of scientifically interesting results in this early publication such as a study on spreading and retraction; the formation of droplets and globules; and interference colors. The clay tablet is one of the first scientific publications known. ${ }^{6}$

The other experiment relevant was also reported by Tabor and also published in the Journal of Colloid \& Interface Science paper. It was a translation of an experiment published on cuneiform clay tablets found in the library of the ruined palace at Nineveh of the King Asshurnabanipal around $750 \mathrm{BC}$. The tablets were brought back to Oxford by George Smith who discovered also the story of Noah and the Flood and of Gilgamesh there. The priests studying oil on water spreading were more interested in applications to necromancy than present fashionable pursuits. More recently, and on a stronger scientific footing, Lord Rayleigh re-did Benjamin Franklin's studies of oleic acid spreading on the surface of a South London pond to make the first quite accurate estimate of molecular size. Franklin started the experiment but got bored and went off to a house of ill repute.

\section{Carbon Dioxide and Natron the Oldest Technol-} ogy. Temperature a Factor

After sodium chloride, natron, sodium bicarbonate, is probably the first industrial scale chemical used by mankind. Natron, in ancient Egypt was essential for mummification. The still little understood, peculiar hydration properties of the bicarbonate ion, in contact with air, affects both tissue dehydration and preserves by sterilization against bacterial degradation. 
The magic of the bicarbonate ion has remained, along with the likewise unexplained problems of Roman and other cements. The foundation of physical chemistry can arguably be marked by Berthollot's observation that reactions are temperature dependent. ${ }^{7}$ He saw soda lime instead of the expected calcium carbonate on the banks of the Nile River during Napoleon's scientific expedition to Egypt in 1792. ${ }^{7}$ This was and is very surprising. Under the high temperature of the sun $\left(>60^{\circ} \mathrm{C}\right)$ when the salt is precipitated from a mix of $\mathrm{Na}^{+}, \mathrm{Ca}^{2+}, \mathrm{Cl}^{-}$, and $\mathrm{HCO}_{3}{ }^{-}$ions in the flood waters the hydration is different from that at $25^{\circ} \mathrm{C}$. But at the very high temperatures in excess of $60{ }^{\circ} \mathrm{C}$ the natural precipitate is sodium bicarbonate.

This profoundly important observation is still universally forgotten, and seems never to have been repeated. Wet sodium bicarbonate is extremely effective in cleaning surfaces. It cuts peptide bonds of proteins bound to saucepans.

Carbon dioxide bubbles in a salt water column are extremely effective in killing viruses as well as bacteria! ${ }^{8-10}$ This is the key to sterilizing and recycling water as is amply illustrated further in papers that follow. The technique is developing fast and successfully for commercial use.

\section{Water, Country Clubs and the British Empire}

For over two centuries the third largest contributor to the economy of the State of Massachusetts was ice from a small lake in the village of Wenham, south of Boston. Very pure water from a small lake froze gradually in winter, so slowly that the ice contained no trapped air and was crystal clear. The ice was sawn up into blocks, covered with hessian bags, and transported by sailing ship around the British Empire from London to the colonies, from India to Jamaica.

During the journey, $2 / 3$ of the ice melted. No selfrespecting Englishman would ever drink his gin and tonic without Wenham ice. This affectation persists. It is claimed that gas free water tastes differently. Perhaps it does. The same can today be achieved using a freezethaw vacuum system but is perhaps somewhat less exotic.

\section{The 4 H's: In Search of Hydration}

The words hydration, hydrophobic, hydrophilic, hydrogen bond are as elusive to pin down as they are universally used. So are other words that are part of the fabric of physical chemistry. The meaning of the four $\mathrm{H}$ words, and others like $\mathrm{pH}$, buffers, surface potentials, water structure are not something a researcher wants to delve into too much. Yet delve into them we must. The 12 member IPAC Commission on $\mathrm{pH}$, for example, rec- ommends that one cannot place any faith in a $\mathrm{pH}$ measurement in a salt solution above 0.1 Molar concentration. Similarly any biologist knows that once a protocol is working, you never play around with the buffer.

Such facts are well known but ignored, and with justification. Because if we do ask questions outside the classical canon we enter a perfect storm. At the other extreme, and for different reasons, $\mathrm{pH}$ measurements on ultra-pure water are also very difficult to make.

To make that explicit:

\section{7a. Water "structure": Bernal's ideas}

The perennial debate on very long ranged water structure vs short range order - hydration - is of long standing. There is no molecular theory of liquids like that underlying statistical mechanical theories of gases or solids. For gases the molecular distribution function is uniform. For solids, the distribution function which is the basis for perturbation is a periodic distribution function (crystal lattice).

Bernal's ideas on the dynamic zeolite-like topology of structures with many membered hydrogen bonded water molecule rings perhaps comes closest to capturing the essence. ${ }^{11}$

\section{7b. Water Structure and Hydration}

While we cannot yet define what we mean by "water structure" the soda lime phenomenon of \# 5 is a clear demonstration that it exists. The specific "affinity" of hydrated cations and anions is different at low and high temperatures.

Indeed, it turns out that water in not "hydrogen bonded" above about $89-90{ }^{\circ} \mathrm{C}$.

If we change water structure by adding an indifferent background electrolyte or sugars or urea, then precipitation of salt crystals, e.g. $\mathrm{Mg}(\mathrm{OH})_{2}$ can be made to vary from microns to nanoparticles to zero in size, as water structure imposed by the background solute changes. ${ }^{12}$

Changing hydration (water structure) with temperature or surfactants affects protein structure and function. ${ }^{13,14}$ Other explicit examples of water structure show up in micellar and microemulsion phase diagrams and with gels. ${ }^{15-17}$

\section{7c. Young, Laplace, vs Poisson and Maxwell and} Hydration

Interfacial tensions and colloidal particle interactions both involve surface induced hydration (or surface water structure). That is a matter of thermodynamics, quantified in principle by Gibbs. Thomas Young's classic work ignored this. Debates about this have continued, 
starting with Laplace vs. Poisson (1832) and a definitive article by J Clerk Maxwell, ${ }^{18}$ (1876) to the present day. At soft surfaces, rough or dynamic on a molecular scale, like phospholipid membranes, these "hydration" forces are repulsive and decay exponentially with a range of the order of the size of a molecule, for water about $3 \AA .^{17}$

At hard surfaces "depletion" forces due to molecular granularity are oscillatory and also repulsive. Molecular granularity includes, for example, micelles that can stabilise emulsions. The periodicity is here of the order of the size of the "pseudo molecules", here micelles. ${ }^{19}$ Similar effects occur with proteins in solution. Our confidence in what we know about water is tempered by the fact that we do not know and cannot predict even the sign of the potential at the air-water interface due to the hydronium vs. hydroxide disposition at the air-water interface. ${ }^{20}$

\section{7d. Hydrogen Bonding and other Heresies}

The concept of a hydrogen bond derives from a perturbation calculation of the interaction between two hydrogen atoms. This has been extended to apply to interactions between two atoms in a sea of its neighbours, an inherently many body problem. Evidently it is nonsense. The strength of what is assigned to a "hydrogen bond" can vary between 0.1 to $10 \mathrm{kT}$ !

The same confusion has become standard for "dipole-dipole" interactions. Thus, the "Keesom force" between two rotating water or protein molecule dipoles is inversely proportional to temperature $\mathrm{T}$. But in a condensed medium it is proportional to temperature due to many body effects.

The distinction made between hydrogen bonding, hydration, van der Waals, permanent dipole or ion dipole forces is completely artificial and erroneous.

It is an artefact of the (mathematical) expansion of an arbitrary distribution of mass or charge into a multipolar Taylor series.

\section{Very Long Ranged Hydrophobic Interactions}

Very long ranged hydrophobic interactions between similar surfaces were first measured and reported by Israelachvili and Pashley in $1982^{21,22}$ based on their experiments using the Surface Forces Apparatus (SFA), which was developed by Israelachvili. Two symmetrical, cleaved and smooth mica surfaces were coated with a hydrophobic surfactant monolayer and the forces between them was measured in various aqueous electrolyte solutions. Comparing these measured forces with the expected van der Waals attractive forces, indicated that there was an additional attractive force, acting over a range of several nanometers, which was identified as a 'long range hydrophobic attraction.' Since then, these attractive forces have been measured at separations up to several hundred nms. The origin of these forces has generated much debate, with the likelihood that their unexpectedly long range is probably related to dissolved gas cavitation created between the hydrophobic surfaces, evidence for which was also observed in the original studies. ${ }^{22,23}$

There are other mechanisms all lumped together in this single mysterious word. Some are due to capillary action..$^{24}$ Some are due to co-operative electrostatic surface molecular correlations and some due to permanent dipolar surface correlations between zwitterionic lipids. ${ }^{25}$ And some are due to polymer bridging between surfaces.

Some are due to nanobubbles. To confuse matters all depend on dissolved atmospheric gas. Many of these forces disappear when dissolved gas is removed from water! ${ }^{26}$

\section{Deconstructing Colloid Science, Physical Chem- istry and Electrochemistry}

As is evident above, the classical theories, even in the continuum solvent approximation are fundamentally flawed. This is due to sins of omission and commission, about which much has been revealed over these past 20 years. $S_{e}{ }^{26}$ and references therein.

Classical theory begins with an ansatz that treats electrostatics and dispersion forces separately. Double layer forces are treated by a nonlinear theory Poisson Boltzmann or HNC say, while dispersion forces are treated by a linear theory (Lifshitz, Hamaker). See Ref. 4 .

This ansatz violates thermodynamics, both the Gibbs adsorption isotherm and the gauge condition on the electromagnetic field. A consequence is that Hofmeister, "specific ion" effects, are ignored. (When the theory is done correctly, they are not.) The result is that practically all force measurements (with the exception of those measured at long range and in very dilute solution) are incorrect and inferences on hydration are also wrong.

Subtracting two partial incorrect theories, double layer and dispersion (van der Waals) forces from an experimental measurement means that the assignment of the residual to "hydration" or specific ion effects is meaningless. So all measurements based on the incorrect theory like $\mathrm{pH}$, pKas, zeta potentials, membrane potentials, ion pumps, activities and interfacial potentials can be incorrect and can be badly so.

\section{Dissolved Gas a Hidden Variable. Cavitation}

There is worse to come. It turns out that dissolved atmospheric gas, we mean not just oxygen or $\mathrm{CO}_{2}$, but 
nitrogen too, has a profound effect. Remove the gas and "hydrophobic" forces go away. Emulsions become stable. ${ }^{26}$ Hofmeister effects reverse and we enter a new world. Simulation does not help and is very misleading. This is because it cannot handle dissolved gas in water. It compares model, gas-free, water or electrolytes or proteins with REAL water and solutions that do contain dissolved gas.

Newton tried to measure molecular forces but gave up, in Art 31 of the Principia, I think, saying "surface combinations were owing". This is not the main problem for us.

\section{Why not Simulation?}

It is impossible to find an answer by computer simulation. The reason will recur. It has nothing to do with the inadequacy and incorrect nature of the molecular potentials used.

The reason is that real water contains dissolved gas. This changes the physico-chemical properties of water drastically. So any computer simulation that does not include dissolved gas is not appropriate to, and does not apply to, real water which does. If it does claim agreement with experimental properties, it is comparing apples with oranges and is wrong.

It is reasonable to think that dissolved atmospheric gas could be ignored.

Consider that the total number of gas molecules in air at $20^{\circ} \mathrm{C}$ and $1 \mathrm{~atm}$ is $0.041 \mathrm{moles} / \mathrm{L}=2.5 \times 10^{19} \mathrm{~mol}-$ ecules $/ \mathrm{mL}$.

The dissolved gas content in water in equilibrium with normal atmospheric pressure at $20^{\circ} \mathrm{C}$ is:

Oxygen: $0.0093 \mathrm{~g} / \mathrm{L}=0.00029 \mathrm{moles} / \mathrm{L}=1.75 \times 10^{17} \mathrm{~mol}-$ ecules $/ \mathrm{mL}$.

Nitrogen: $0.0148 \mathrm{~g} / \mathrm{L}=0.00053$ moles $/ \mathrm{L}=3.17 \times 10^{17}$ molecules $/ \mathrm{mL}$.

Total gas molecules in water is 0.00085 moles $/ \mathrm{L}=5.1 \mathrm{x}$ $10^{17}$ molecules $/ \mathrm{mL}$.

The number of water molecules in liquid water is 55 moles/L. Hence, they differ by a factor of about $10^{5}$.

Such a small number of impurity molecules would be impossible to deal with in a simulation. (This is around the CMC of a surfactant like SDS in $0.3 \mathrm{M}$ salt).

But it really does matter!

In another important example: acceptable or potable water has to be at least $99.99 \%$ pure, that is less than $1.0 \mathrm{mM} \mathrm{NaCl}$ ! Small 'contaminants' matter but so can drinking ultra-pure water, which can cause death by hyponatremia or water poisoning by reducing sodium levels in your blood. Sports electrolyte drinks prevent this. The famous medical doctor Paracelsus told us this about too much water. As already remarked, the origins of long ranged hydrophobic interactions most likely lie with the presence of dissolved gas also.

The tensile strength of water depends on 'inert' dissolved atmospheric gas molecules. They act in the same way as impurities in a solid to reduce its strength according to a well known theory of Griffiths. The tensile strength of water is two orders of magnitude less than that we would calculate from molecular forces. It gives rise to cavitation, which only occurs because of the presence of dissolved gases. The energy cost of cavitation on shipping is a huge economic impost on society. So control by removal of gas will yield enormous energy savings. We will see how it can be accomplished in what follows.

\section{Water, Salt and Bubbles}

The debacle has hardly begun. This, perhaps simplest of all experiments remains unexplained: ${ }^{27}$

Gas passed through a porous frit ascends as bubbles in a column of water. They collide, and fuse to form bigger bubbles. The column stays clear (like a fish tank). If a salt like $\mathrm{NaCl}$ is added, above a critical concentration centred around $0.17 \mathrm{M}$ the bubbles do not fuse. The column becomes a densely packed foam of tiny bubbles. The critical concentration is the same ionic strength as that of the blood of land animals and that of the Permian ocean from which we emerged. The reason is not incidental and irrelevant.

To make matters worse, for some salts no such effect is observed. Bubbles happily fuse in salt solutions up to $6 \mathrm{M}$. There are rules without exceptions that show which ion pairs give rise to fusion and which do not, and also rules for mixtures.

This is still a complete mystery that has defied explanation and has been ignored for over 30 years. It is a phenomenon that the new technologies of this volume exploit.

\section{Nanobubbles and Bubble Fusion}

A history of nanobubbles is given in Reference 29 . By these we mean gas filled entities of the order of a nanometer in size or above. They are if we like the analogue of micelles. It was argued until recently that they could not exist as stable entities, although what "stable" meant is unclear. That consensus was arrived at by applying macroscopic concepts to nanometric objects to which macroscopic arguments cannot apply. It is now agreed that nanobubbles do exist in salt water regardless of theory. ${ }^{28-30}$

Gas containing small bubble structures have been much studied by laser spectroscopy and appear to be involved in enzyme catalysis via cavitation, in the active sites of enzymes. ${ }^{31}$ Their formation and stability in elec- 
trolytes is long lived above $0.17 \mathrm{M}$ and probably explains the bubble-bubble fusion inhibition phenomenon.

\section{Jellyfish}

Just as old as the problem of why ice floats on water, or why bubbles do not fuse in salt water is that of the very existence of jellyfish, and other soft bodied multicelled animals. These emerged in the Ediacaran Era 570 million years ago before the Cambrian Era. It was first raised by Gorter and dismissed by the establishment at a Faraday Conference in $1930 .{ }^{1}$ The problem is that jellyfish contain $<<1-2 \%$ non-aqueous matter. Any such matter is confined to digestive and reproductive regions. If that is so the jellyfish carapace must be essentially pure water. This rubbery solid matter exists surrounded by an ocean that contains at least $3 \%$ salts. Its existence Chinese people preserve and eat it - defies the laws of osmotic pressure; and the diffusion equation. ${ }^{1}$

On the face of it, there is little to answer the inference that here is a new state of water with very long ranged macrostructure. That could be resolved by some straightforward experiments. Like measurement of conductivity and careful elemental composition studies. The existence of jellyfish - for 600 million years defies conventional wisdom and yet the problem continues to be ignored except by brave souls like J. Pollack. (See however remarks below on very long range forces between conducting polymers.)

\section{The Polywater Debacle}

The jellyfish conundrum is resolved by some by postulating the existence of a new state of water structures over tens of thousands of nanometers. Such a "solution" is a tautology. It was a trap into which the renowned Russian colloid scientist fell into with the discovery of the much derided "polywater". For an account of this and associated events see Ref 32. Polywater does exist but is due to polymeric impurities. Between conducting thin linear charged polymers there are very long range, many body interactions, which are a hidden driver of organisation and recognition. ${ }^{26,33-35}$

The same forces occur for polyelectrolytes and also for DNA. ${ }^{36}$ They have been known almost since the discovery of van der Waals dispersion forces and ignored.

\section{Problems and Solutions}

We can continue in this mould, listing words without limit that remind us that the foundations are insecure - chirality, magnetic fields, clouds and rain, for a start. The surface tension of water? Forget it.

The problems associated with water seem to have become deeper with the increasing reliance on, and now dominance of unreasonable Aristo-Platonic approaches to chemistry. These abjure experiment in favour of simulation with fixed concepts that assign insight to mindless computer games. These can sometimes fit data but never predict. It is a curious constraining and lazy reversion to medievalism.

We can consider this reversion a catastrophe or an opportunity. Awareness of the defects of present theory allows us to throw off the shackles. The major source of hubris and of omission in theories is that of air, the fourth ${ }^{\mathrm{t}}$ element of the Greeks.

In retrospect, Descartes might better have said: "I breathe; therefore I am" instead of his famous impotent Platonic assertion: "I think: therefore I am".

Thales of Miletus, the oldest known Greek scientist, thought the world consisted in two parts: water and God.

\section{Desalination and Aristotle}

The technology is not new. Aristotle described a desalination technique in the $4^{\text {th }}$ century BC in Meteorologica. There's even a mention of desalination (although vague) in the Bible (Exodus 15:22-26).

"Desalination has been around for millennia if you count the evaporation techniques pioneered by the ancient Greek. Sailors in the $4^{\text {th }}$ century BC boiled salt water and then captured the steam. When cooled, steam condenses into distilled water that's free of virtually all contaminants."

https://ideas.ted.com/would-you-drink-desalinatedseawater-recycled-sewage-water-get-ready-to-find-out/

Plans for desalination-removing salt from seawater-date back to $4^{\text {th }}$ century B.C. from ancient Greek philosopher Aristotle, according to livescience.com. Action was put into place around 200 A.D. when sailors desalinated seawater with boilers on their ships.

https://www.pumpsandsystems.com/desalinationprojects-picking-challenges-remain

\section{Leonardo da Vinci's View}

It is impossible to assert with confidence what people meant by words written in a different world 500 years ago. Leonardo's science seems to have been sniffily dismissed because he did not know Latin and Greek, Plato and Aristotle, the mantles of the Renaissance Cogniscenti. But he seems to have been of the same view as Roger Bacon and Kant. And as d'Arcy Thompson said:

Kant said of the chemistry of his day and generation that it was a science but not a Science - in that the criterion of true science lay in its relation to mathematics. ${ }^{37}$ 
(By that he included physics too). He tells us too that Leonardo da Vinci $(1452$ - 1519) who died 500 years ago thought the same: ${ }^{38}$

Nissuna umana investigazione si pò dimandare vera scienzia s'essa non passa per le matematiche dimostrazioni, e se tu dirai che le scienzie, che principiano e finiscono nella mente, abbiano verità, questo non si concede, ma si niega, per molte ragioni, e prima, che in tali discorsi mentali non accade esperienzia, sanza la quale nulla dà di sé certezza.

(No human enquiry can call itself a true science unless it proceeds by means of mathematical demonstrations, and if you claim that the sciences that begin and end in the mind possess some truth, this is not conceded, but is denied for several reasons, the first being that in such mental arguments no experience occurs, without which nothing is certain).

And Xenophanes said:

The gods have not revealed all things from the beginning.

But men seek and so find out better in time,

Let us suppose these things are like the truth.

But surely no man knows or ever will know

The truth about the gods and all I speak of.

But even if he happens to tell the perfect truth, he does not

know it, but appearance is fashioned over everything.

We borrowed Xenophanes words of motivation and inspiration from Morris Klines' marvellous book 'Mathematics: The Loss of certainty.'

This present volume takes air with salts and water and puts them to work for novel water technologies, regardless of theory. We take that as our text and so to work.

Postscript Since this essay was written the very long range forces between conducting cylinders, or polyelectrolytes have begun to surface as serious hidden variables, in phenomena associated with physiology in the previously mysterious endothelial surface layer ${ }^{28}$ and other anomalous properties that occur with the fuel cell polymer Nafion. ${ }^{39-40}$

These developments, connected to Chinese acupuncture confirm the perpetual fact that water always surprises.

\section{REFERENCES}

1. M. Henry, The state of water in living systems: from the Liquid to the Jellyfish in Aqua Incognita. Why Ice Floats on Water and Galileo 400 years on, pp 51-99 Connor Court Publishing Pty Ltd. Copyright 2014 Pierandrea Lo Nostro and Barry W Ninham Eds.

2. The route of the ancient shipping route from Greece through the Karakum desert of Turkmenistan and beyond to the lost city of Alexandria on the old Oxus in Afghaistan has been explored and rediscovered by Australian photo journalist David Adams.

3. S. J. Louis Caruana in Aqua Incognita From Water to the Stars: A reinterpretation of Galileo's style and Dava Sobel, Galileo's Daughter.

4. Aqua Incognita Why Ice Floats on Water and Galileo 400 Years on. Editors: P. Lo Nostro and B. W. Ninham, 2014, 516 pp. Connor Court publishers Ballarat, Victoria.

5. S. Andersson, B. W. Ninham, Why Ice Floats on Water, Solid State Science, 2003, 5 (5), 683-693.

6. D. Tabor, Quotes from British Museum, Cuneiform Texts from Babylonian Tablets in British Museum, Vol. 5, Plate IV, 22446, London, 1898, J. Colloid Interface Sci., 1980, 75, 240 - 245

7. Scientific Aspects of the French Egyptian Expedition 1798-1801 Author(s): Charles Coulston Gillispie Source: Proceedings of the American Philosophical Society, Vol. 133, No. 4 (Dec, 1989), pp. 447- 474, Published by: American Philosophical Society Stable, Accessed: 07-01-2016 12:50 UTC.

8. A. G. Sanchis, R.M. Pashley, B.W. Ninham, Water sterilisation using different hot gases in a bubble column reactor, J. Environ. Chem. Eng., 2018, 6, 26512659.

9. A. G. Snachis, R. M. Pashley, B. W. Ninham, Low temperature MS2 (ATCC15597-B1) virus inactivation using a hot bubble column evaporator (HBCE), Colloids Surf. B Biointerfaces, 2016, 151, 1-10.

10. A. G. Sanchis, R. M. Pashley, B. W. Ninham, Virus and bacteria inactivation by $\mathrm{CO}_{2}$ bubbles in solution, NPJ Clean Water, 2019, v2 Number 1.

11. S. T. Hyde, Aqua reticulata: topology of liquid water networks, in Aqua Incognita, 145-175.

12. R. Giorgi, C. Bozzi, L. Dei, C. Gabbiani, B. W. Ninham, P. Baglioni, Nanoparticles of $\mathrm{Mg}(\mathrm{OH})_{2}$ : Synthesis and Application to Paper Conservation, Langmuir, 2005, 21 (18), 8495-8501.

13. A. E. Voinescu, P. Bauduin, C. Pinna, D. Touraud, B. W. Ninham, W. Kunz, Similarity of salt influences on the $\mathrm{pH}$ of buffers, polyelectrolytes and proteins, $J$. Phy. Chem. B, 2006, 110 (17), 8870-8876. 
14. R. Waninge, M. Paulsson, T. Nylander, B. W. Ninham, P. Sellers, Binding of sodium dodecyl sulphate and dodecyl trimethyl ammonium chloride to beta -lactoglobulin: A Calorimetric Study, Int. Dairy J., 1998, 18 (2), 141-148.

15. I. Lisiechi, M. B. Orling, L. Motte, B. W. Ninham, M. P. Pileni, Synthesis of copper nanosize particles in anionic reverse micelles: Effect of the addition of a cationic surfactant on the size of the crystallites, Langmuir, 1995, 11 (7), 2385-2392.

16. P. Andre, A. Filankembo, I. Lisiecki, C. Petit, T. Gulik-Krzywicki, B.W. Ninham, M. P. Pileni, Supraaggregation: Microphase formation in complex fluids, Adv. Mater., 2000, 12, 119-123.

17. The literature on hydration and controlled nanoparticle synthesis in cationc microemulsions is very large now. The Authors' book provides an entry point Molecular Forces and Self Assembly In Colloid, Nano Sciences and Biology, Cambridge UP, 2010, B. W. Ninham and P. Lo Nostro.

18. J. Clerk Maxwell: Capillary Action. Encyclopaedia Britannica, 9th ed.; 1876. See also his "Collected Works".

19. R. M. Pashley, B. W. Ninham, Double-layer forces in ionic micellar solutions, J. Phy. Chem., 1987, 91 (11), 2902-2904.

20. T. Duignan, D. F. Parsons and B. W. Ninham Hydronium and Hydroxide at the Air-Water Interface with a Continuum Solvent Model, Chem. Phys. Lett, 2015, 635, 1-12.

21. J. N. Israelachvili, R. M. Pashley, The hydrophobic interaction is long-range, decaying exponentially with distance, Nature, 1982, 300, 341-342.

22. J. N. Israelachvili, R. M. Pashley, Measurement of the hydrophobic interaction between two hydrophobic surfaces in aqueous electrolyte solutions, J. Colloid Interface Sci., 1984, 98, 500-514.

23. R. M. Pashley, P. M. McGuiggan, B. W. Ninham, D. F. Evans, Attractive forces between uncharged hydrophobic surfaces: Direct measurements in aqueous solutions, Sci., 1985, 229, 1088-1089.

24. V. V. Yaminsky, S. Ohnishi, B. W. Ninham. LongRange Hydrophobic Forces are due to Capillary Bridging. In: Handbook of Surfaces and Interfaces of Materials, Academic Press: New York, 2001, 4, 131227.

25. P. Kekicheff. Adv. Coll. Interface Sci, 2019, 270, 191215.

26. B. W. Ninham, R. M. Pashley, P. Lo Nostro, Surface forces: Changing concepts and complexity with dissolved gas, bubbles, salt and heat, Curr. Opin. Colloid Interface Sci., 2016, 27, 25-32.
27. V. S. J. Craig, B. W. Ninham, R. M. Pashley, The Effect of Electrolytes on Bubble Coalescence in Water, J. Phy. Chem., 1993, 97 (39), 10192-10197.

28. B. P. Reines, B. W. Ninham, Structure and function of the endothelial surface layer: unraveling the nanoarchitecture of biological surfaces, Quarterly Reviews of Biophy., 2019, 52, 1-11.

29. M. Alheshibri, J. Qian, M. Jehannin, V. S. Craig, A history of nanobubbles, Langmuir, 2016, 32(43), 11086-11100.

30. N. F. Bunkin, , B. W. Ninham, P. S. Ignatiev, V. A. Kozlov, A. V. Shkirin, A. V. Starosvetskij, Long living nanobubbles of dissolved gas in aqueous solutions of salts and erythrocyte suspensions, J. Biophotonics, 2011, 4(3), 150-164.

31. Kim, H.-K., E. Tuite, B. Norden, B. W. Ninham, Coion dependence of DNA nuclease activity suggests hydrophobic cavitation as a potential source of activation energy, Eur. Phys. J., 2001, 4, 411-417.

32. B. V. Derjaguin, J. Theo, G. Overbeek, Their Times, and Ours, Barry W. Ninham, Substantia, 2019, 3(2), 65-72. P. Lo Nostro, B. W. Ninham, After DLVO: Hans Lyklema and the keepers of the faith, Adv. Colloid Interface Sci., 2020, 276, 102082.

33. B. Davies, B. W. Ninham, P. Richmond, Van der Waals forces between thin cylinders: new features due to conduction processes, J. Chem. Phys., 1973, 58(2), 744-750.

34. N. F. Bunkin, P. N. Bolotskova, S. V. Gudkov, Y. Juraev, M. S. Kiryanova, V. A. Kozlov, B. W. Ninham, R. S. Safronenkov, A. V. Shkirin, E. V. Uspenskaya, Structure and Properties of the Exclusion zone of Nafion: Swelling in a constrained volume, ACS Omega, 2020.

35. N. F. Bunkin, A. V. Shkirin, V. A. Kozlov, B. W. Ninham, E. V. Uspenskaya, S. V. Gudkov, Near-surface structure of Nafion in deuterated water, J. Chem. Phys., 2018, 149, 164901.

36. K. L. Jimenez-Monroy, N. Renaud, J. Drijkoningen, D. Cortens, C. van Haesendonck, W. J. Guedens, J. V. Manca, L. D. A. Siebbeles, F. C. Grozema, P. H. Wagner, High Electronic Conductance through Double-Helix DNA Molecules with Fullerene Anchoring Groups, J. Phys. Chem. A, 2017, 121, 1182-1188.

37. D. W. Thompson, Growth and Form. Cambridge University Press, 1917.

38. L. Da Vinci, Treatise on Painting, Codex Rurbinas Latinus, transl. and annotated by P. P. McMachon, Princeton University Press, 1956.

39. N. F. Bunkin, P. N. Bolotskova, S. V. Gudkov, Y. Juraev, M. S. Kiryanova, V. A. Kozlov, B. W. Ninham, R. S. Safronenkov, A. V. Shkirin, E. V. Uspenskaya, 
Structure and Properties of the Exclusion zone of Nafion: Swelling in a constrained volume, ACS Omega, 2020.

40. N. F. Bunkin, A. V. Shkirin, V. A. Kozlov, B. W. Ninham, E. V. Uspenskaya, S. V. Gudkov, Near-surface structure of Nafion in deuterated water, J. Chem. Phys., 2018, 149, 164901. 